\title{
Fever During Pregnancy: Etiology and Fetomaternal Outcomes
}

\author{
Rinnie Brar $^{1} \cdot$ Vikas Suri $^{2} \cdot$ Vanita Suri $^{1} \cdot$ Mini P. Singh $^{3} \cdot$ Manisha Biswal $^{4} \cdot$ Pooja Sikka $^{1}$
}

Received: 27 June 2021 / Accepted: 30 August 2021 / Published online: 14 September 2021

(c) Federation of Obstetric \& Gynecological Societies of India 2021

\begin{abstract}
Purpose Etiological spectrum of fever in pregnant women and its impact on fetomaternal outcomes were studied.

Methods This was a hospital-based prospective study, conducted over 12 months. All pregnant women with fever were screened and detailed etiological evaluation carried out. Maternal and foetal outcomes were noted.

Results One hundred and eighty-one pregnant women with fever were included. Common causes were dengue 44 (24.3\%), hepatitis E 26 (14.4\%) and urinary tract infection (UTI) 22 (12.2\%). Mosquito-borne diseases accounted for the highest burden 61 (33.7\%). Second most common were diseases transmitted by feco-oral route 46 (25.4\%). Maternal deaths occurred in 29 (16\%) patients. Common causes of death were hepatitis E infection in 9 of $26(34.6 \%)$ cases, dengue in 7 of $44(15.9 \%)$ and tuberculosis in 5 of $11(45.5 \%)$ cases.

Conclusion Dengue, hepatitis E and UTI were the most common causes of fever during pregnancy. Most cases were caused by vector- and water-borne diseases and thus potentially preventable. Overall maternal mortality was $16 \%$.
\end{abstract}

Keywords Maternal fever $\cdot$ Dengue $\cdot$ Hepatitis E $\cdot$ Urinary tract infection

\section{Introduction}

Rinnie Brar in Department of obstetrics and gynaecology, Postgraduate Institute of Medical Education and Research, Sector 12, Chandigarh, 160012, India; Vikas Suri in Department of internal medicine, Postgraduate Institute of Medical Education and Research, Chandigarh, India; Vanita Suri in Department of obstetrics and gynaecology, Postgraduate Institute of Medical Education and Research, Sector 12, Chandigarh, 160012, India; Mini P. Singh in Department of virology, Postgraduate Institute of Medical Education and Research, Chandigarh, India; Manisha Biswal in Department of medical microbiology, Postgraduate Institute of Medical Education and Research, Chandigarh, India; Pooja Sikka Department of obstetrics and gynaecology, Postgraduate Institute of Medical Education and Research, Sector 12, Chandigarh, 160012, India.

Pooja Sikka

drpoojasikka@yahoo.com

1 Department of Obstetrics and Gynaecology, Postgraduate Institute of Medical Education and Research, Sector 12, Chandigarh 160012, India

2 Department of Internal Medicine, Postgraduate Institute of Medical Education and Research, Chandigarh, India

3 Department of Virology, Postgraduate Institute of Medical Education and Research, Chandigarh, India

4 Department of Medical Microbiology, Postgraduate Institute of Medical Education and Research, Chandigarh, India
Most of the efforts to reduce maternal mortality in India have focussed on haemorrhage, hypertension and sepsis. There is little focus on the impact of infectious diseases on maternal, foetal and neonatal outcomes, which is demonstrated by the lack of well-conducted prospective studies in the literature.

Owing to the anatomical and physiological changes, certain infections such as urinary tract infections (UTI) are more common during pregnancy [1]. Infections like Plasmodium falciparum malaria, hepatitis $\mathrm{E}$ and $\mathrm{H} 1 \mathrm{~N} 1$ influenza are more severe in pregnancy due to changes in the immune system [2]. However, the contribution of these infections towards maternal mortality and near-miss morbidity is not clear. Therefore, they should be incorporated in the national maternal mortality data in greater detail. Only few studies have been conducted on the impact of fever on fetomaternal outcomes [3]. It is postulated that with the development of maternal death surveillance and response (MDSR) guidelines established by Government of India in 2017, more information will be available on the morbidity and mortality burden of these diseases [4].

Causes of fever during pregnancy and its course and outcomes should be studied in detail. This knowledge will 
improve maternal and foetal management and pregnancy outcomes. This is particularly important in the countries like India which have an immense burden of infectious diseases. Hence, this study was designed to fill the gaps in knowledge on the etiological spectrum of fever in the antenatal period in Northern India and its impact on maternal and feto-neonatal outcomes.

\section{Methods}

This was a hospital-based prospective study, conducted over a period of 12 months from 1 July 2016 to 30 June 2017. The study was conducted in Post Graduate Institute of Medical Education and Research, Chandigarh, a tertiary care centre in Northern India. The institute caters to the regions of Chandigarh, Punjab, Haryana, Himachal Pradesh and Jammu \& Kashmir and is a major referral centre for high-risk pregnancies. The study was approved by institutional ethics committee and has been performed in accordance with the ethical standards laid down in the 1964 Declaration of Helsinki and its later amendments. Written informed consent was obtained from all subjects.

All pregnant women presenting with fever over the course of study period were screened. 216 women presented with fever, of whom, non-consenting women, women with history of pelvic instrumentation and women with history of ruptured membranes were excluded, and 181 patients were recruited in the study. Fever was defined as a.m. temperature of $>37.2^{\circ} \mathrm{C}\left(98.9^{\circ} \mathrm{F}\right)$ or p.m. temperature of $>37.7^{\circ} \mathrm{C}\left(99.9^{\circ} \mathrm{F}\right)[5,6]$.

Detailed medical history, examination and investigations were performed, and all the data were recorded on case record sheets.

\section{Laboratory Investigations}

All cases underwent investigations as per the standard protocol followed in obstetric emergency including haemoglobin, complete and differential blood counts, serum electrolytes, urea and creatinine, liver function tests. Samples for blood cultures were obtained and tested using automated blood culture systems (BD BACTECTM). A $10 \mathrm{ml}$ of mid-stream urinary sample was obtained, and urine microscopic examination as well as culture by inoculation onto CLED medium was carried out. Additionally, investigations to elucidate the etiology of fever that were carried out in all patients as per Table 1.

Further testing was done depending on the clinical profile. Ziehl-Neelsen staining from early morning sputum smears or body fluid smears for acid fast bacillus testing was performed to diagnose tuberculosis. This was supported with Mycobacteria Growth Indicator Tube (MGIT) or polymerase chain reaction where clinical suspicion was high. Sputum culture was performed whenever lower respiratory tract infections were suspected. Chest X-ray using abdominal lead shield protection was added as an adjunct, wherever indicated. Nasopharyngeal swabs were tested with real-time polymerase chain reaction (RT-PCR) for pandemic $\mathrm{H} 1 \mathrm{~N} 1$ influenza testing as per CDC protocol, wherever indicated. Patients with suspected viral hepatitis were tested as per Table 2.

Tzanck smear was performed from vesicles wherever patients presented with fever and vesicular rash. RT-PCR for chikungunya was performed wherever indicated, RT-PCR and IgM antibodies if presentation was within 1 week of onset of symptoms, and IgM antibodies (SD Bioline, Korea) if presentation was more than 1 week after symptom onset.

Neuro-imaging, cardio-imaging and abdominal imaging were performed wherever required based on the clinical

Table 1 Investigations to elucidate the specific etiology of fever carried out in all women

\begin{tabular}{|c|c|}
\hline Etiology & Investigation \\
\hline Malaria & $\begin{array}{l}\text { Peripheral blood thin smears examined for malarial parasites on } 3 \text { successive days and rapid immune-chromatographic tests for } \\
\text { malarial antigen (based on the detection of histidine-rich protein } 2 \text { from Plasmodium falciparum and parasite-specific lactate } \\
\text { dehydrogenase (pLDH) (Nicholas Piramal, India, and SD Bioline, Korea) performed to diagnose malaria infection and causa- } \\
\text { tive species of Plasmodium }\end{array}$ \\
\hline Dengue & $\begin{array}{l}\text { Dengue IgM antibodies were detected using ELISA (NIV, Pune) if presentation was more than } 3-5 \text { days after the onset of clinical } \\
\text { symptoms and/or NS1 antigen assay (Pan Bio, Queensland, Australia) if the presentation was within 3-5 days within onset of } \\
\text { clinical symptoms }\end{array}$ \\
\hline Enteric fever & $\begin{array}{l}\text { Blood was cultured to detect Salmonella typhi as well as paratyphi A and Widal tube agglutination test performed for serological } \\
\text { diagnosis of enteric fever }\end{array}$ \\
\hline Leptospira & IgM ELISA (SD Bioline, Korea) or microscopic agglutination test (MAT) \\
\hline Scrub typhus & $\begin{array}{l}\text { PCR for scrub typhus (if presentation was within } 10 \text { to } 15 \text { days of onset of symptoms) and IgM ELISA (InBios, Fullers laborato- } \\
\text { ries, USA) if fever was more than } 7 \text { days }\end{array}$ \\
\hline
\end{tabular}


Table 2 Evaluation of patients with suspected viral hepatitis

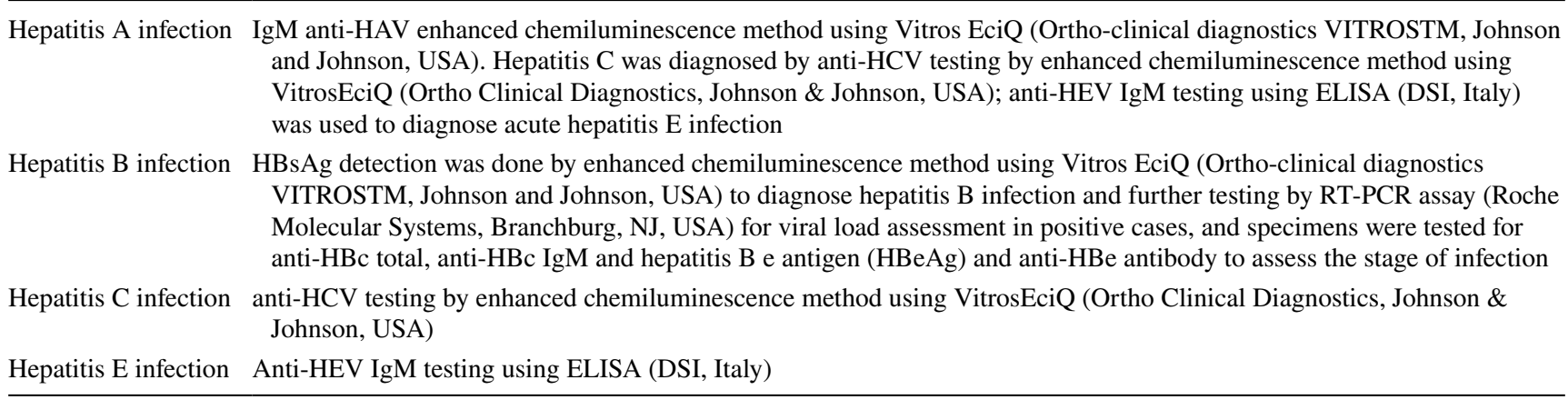

assessment of each patient. Ultrasound for foetal assessment was performed by obstetric consultants in the department of obstetrics and gynaecology of the Institute. Dating, foetal weight, malformations, liquor and bio-physical profile were assessed.

All women were managed according to the institute protocol. Supportive management, anti-pyretics and specific anti-microbial therapy according to laboratory investigations were prescribed. Women were reviewed again after discharge from hospital. Further, all women were followed up till delivery and maternal and feto-neonatal outcomes were noted.

\section{Results}

The study included 181 pregnant women with fever. Etiology of fever and maternal outcomes were assessed for all 181 patients. Out of total 181, 175 (96.7\%) patients were given a specific diagnosis, of whom 156 patients had laboratory evidence of disease and 19 were clinically diagnosed (upper respiratory tract infection $(\mathrm{URTI})=11$, gastroenteritis $=8$ ). A specific diagnosis could not be reached in 6 (3.3\%) patients (Table 3). Details of the 11 (6.1\%) patients with recurrent episodes of fever are listed in Table 4.

The average age of patients was $28.6 \pm 2.88$ (range: 18-37) years with 147 (81.3\%) cases presenting in the 3rd trimester of pregnancy (Table 4). Most (80 (44.2\%)) women had residence in Chandigarh tricity area, 32 (17.7\%) were from Punjab and 26 (14.4\%) from Haryana. Twenty-five $(13.8 \%)$ women were unbooked.

Seventeen $(9.4 \%)$ patients had received antibiotics before presentation, and all were empirical in nature. All antibiotics were penicillins (co-amoxyclav, cephalosporins, piperacillin-tazobactam) except 1 patient who had been started on chloroquine empirically.

As a group, mosquito-borne diseases were responsible for the highest burden accounting for 61 (33.7\%) cases. This included dengue in $44(24.3 \%)$, malaria in $11(6.1 \%)$ and chikungunya fever in $6(3.3 \%)$. The second most common group were diseases transmitted by feco-oral route accounting for $46(25.4 \%)$ cases. This included hepatitis $\mathrm{E}$ in $26(14.4 \%)$, gastroenteritis in $8(4.3 \%)$, hepatitis A in $6(3.3 \%)$, typhoid in $5(2.7 \%)$ and liver abscess in $1(0.6 \%)$ patient.

Dengue was the most common cause of fever followed by hepatitis E and UTI (Table 5). Of 44 patients with dengue, $27(61 \%)$ demonstrated positivity for NS1 antigen and out of these, $24(89 \%)$ presented within 5 days of symptom onset. Seventeen $(39 \%)$ patients had IgM positivity at admission. Twenty-two $(50 \%)$ patients had dengue with warning signs (WHO definition), while 14 (31.8\%) patients had severe dengue (WHO definition) at admission; of these, 7 patients died and 7 were classified as maternal near-miss cases (WHO MNM criteria). There were 2 miscarriages, 4 still births, 15 pre-term births, 13 low birth weight babies and 2 neonatal deaths.

Twenty-two patients had UTI of whom 12 (46\%) had pyelonephritis. Twelve patients had urine culture positivity for Escherichia coli, 6 for Klebsiella spp, 1 for Pseudomonas aeruginosa and 1 for Proteus mirabilis. Both urine and blood cultures were positive in 2 patients $(1=$ Escherichia coli, $1=$ Klebsiella spp). All patients were treated with appropriate antibiotics based on culture and sensitivity reports and safety of antibiotic use in pregnancy. Most commonly used antibiotics were nitrofurantoin, ceftriaxone and piperacillin-tazobactam. Four patients required drainage of pyonephrosis/perinephric collections. Five women developed oligohydramnios, 9 had pre-term births, 9 low birth weight babies and 1 still birth.

Thirty-six (19.9\%) patients had febrile jaundice, of whom $26(14.4 \%)$ had hepatitis E, $6(3.3 \%)$ had hepatitis A, 2 $(1.2 \%)$ had malaria, $1(0.6 \%)$ had cholangitis and $1(0.6 \%)$ had liver abscess. A high rate of poor pregnancy outcomes was noted in women with hepatitis $\mathrm{E}$ infection evidenced by $9(34.6 \%)$ maternal deaths, $8(30 \%)$ still births, $10(38 \%)$ pre-term births, $13(50 \%)$ low birth weight babies and 1 miscarriage.

Overall, 29 (16\%) patients died. Of the $152(84 \%)$ women were discharged alive, 33 (18.2\%) were near miss. Common causes of death were hepatitis $\mathrm{E}$ infection in 
Table 3 Etiology of fever among pregnant women

\begin{tabular}{|c|c|c|}
\hline Cause & $n=181(\%)$ & Positive laboratory results/clinical diagnosis \\
\hline \multicolumn{3}{|l|}{ Viral diseases } \\
\hline Dengue & $44(24.3)$ & $27(61 \%)$ were NS1 antigen positive, $17(39 \%)=\operatorname{IgM}$ antibody positive \\
\hline Hepatitis E & $26(14.4)$ & $26(100 \%)$ were anti-HEV IgM antibody ELISA positive \\
\hline Hepatitis A & $6(3.3)$ & $6(100 \%)$ were anti-HAV IgM antibody ELISA positive \\
\hline Chikungunya & $6(3.3)$ & $6(100 \%)$ were IgM antibodies positive on immunochromatography \\
\hline Chicken pox & $5(2.7)$ & $\begin{array}{l}5(100 \%) \text { had vesicular rash Tzanck smear depicted acanthocytes and syncitial giant cells; clinical } \\
\text { judgement }\end{array}$ \\
\hline H1N1 influenza & $3(1.7)$ & $3(100 \%)$ RT-PCR positive from nasopharyngeal swabs \\
\hline Acute Hepatitis B infection & $1(0.6)$ & $\begin{array}{l}\text { Clinical diagnosis; deranged liver function tests; high titre positivity to anti-HBc; and negativity to } \\
\mathrm{HBeAg} \text { and hepatitis } \mathrm{A}, \mathrm{C} \text { and } \mathrm{E} \text { markers }\end{array}$ \\
\hline \multicolumn{3}{|l|}{ Bacterial diseases } \\
\hline UTI & $22(12.1)$ & $\begin{array}{l}22(100 \%) \text { had urine culture positive (Escherichia coli, Klebsiella spp, Proteus mirabilis and Pseu- } \\
\text { domonas aeruginosa); } 2 \text { had blood culture positivity (Escherichia coli) }\end{array}$ \\
\hline Tuberculosis & $11(6.1)$ & $\begin{array}{l}7 \text { patients had pulmonary tuberculosis diagnosed by sputum } \mathrm{ZN} \text { staining } \pm \text { sputum for MGIT } \pm \text { chest } \\
\text { X-ray findings; } 1 \text { patient had spinal tuberculosis diagnosed clinically adjuncted by MRI findings; } 1 \\
\text { patient had miliary tuberculosis with sputum AFB positive; and } 2 \text { patients had tubercular meningi- } \\
\text { tis with suggestive neuro-imaging and CSF positive for AFB } \pm \text { MGIT }\end{array}$ \\
\hline Scrub typhus & $6(3.3)$ & PCR positivity in $3(50 \%)$ patients, $\operatorname{IgM}$ positivity in $5(83.3 \%)$ patients \\
\hline Typhoid & $5(2.7)$ & $5(100 \%)=$ Salmonella typhi septicaemia demonstrated on blood culture \\
\hline Leptospirosis & $1(0.6)$ & Positive IgM ELISA \\
\hline \multicolumn{3}{|l|}{ Others } \\
\hline Malaria & $11(6.1)$ & $\begin{array}{l}9(82 \%) \text { had Plasmodium vivax on peripheral blood smear/RDT, } 1(9 \%) \text { had Plasmodium falciparum } \\
\text { positive blood smear/RDT, and } 1(9 \%) \text { had co-infection with both Plasmodium vivax and falcipa- } \\
\text { rum }\end{array}$ \\
\hline URTI & $11(6.1)$ & $\begin{array}{l}11(100 \%) \text { based on clinical diagnosis with positive history and examination; no evidence of lower } \\
\text { respiratory tract infection and no evidence of bacterial septicaemia; and H1N1 not tested as CDC } \\
\text { criteria not met for testing }\end{array}$ \\
\hline Gastroenteritis & $8(4.3)$ & $\begin{array}{l}8(100 \%) \text { based on clinical diagnosis with positive history; stool routine examination normal, stool } \\
\text { and blood cultures negative }\end{array}$ \\
\hline Pneumonia & $6(3.3)$ & $\begin{array}{l}6(100 \%) \text { based on chest X-ray findings, positive sputum culture; } 4 \text { (67\%), Klebsiella spp, } 2(33 \%) \text {, } \\
\text { streptococcus pneumoniae; and } 2(33 \%), \text { blood culture positive }\end{array}$ \\
\hline Parotitis & $1(0.6)$ & Diagnosed based on clinical and ultrasonography findings \\
\hline Cholecystitis-cholangitis & $1(0.6)$ & Described in Table 2 \\
\hline Liver abscess & $1(0.6)$ & Radiological diagnosis in patient with febrile jaundice; required pig tail drainage of empyema \\
\hline Unclear diagnosis & $6(3.3)$ & \\
\hline
\end{tabular}

$A F B$ acid fast bacillus, $C D C$ centre for disease control, $C S F$ cerebrospinal fluid, $M G I T$ mycobacteria growth indicator tube, $R D T$ rapid diagnostic tests, URTI upper respiratory tract infection, UTI urinary tract infection

Table 4 Causes of recurrent fever among pregnant women

\begin{tabular}{lll}
\hline Etiology & $n=11$ & Details \\
\hline $\begin{array}{l}\text { Unevaluated } \\
\text { Recurrent UTI }\end{array}$ & 4 & $\begin{array}{l}\text { History suggestive of URTI } \\
\text { Both the previous episodes had urine culture positivity for Escherichia coli. Ultrasonography revealed small lower } \\
\text { calyceal calculi } \\
\text { 1 = spinal tuberculosis, } 1=\text { lymph node tuberculosis, } 2=\text { pulmonary tuberculosis; all } 4 \text { patients were on anti-tuber- } \\
\text { cular therapy (continuation phase regimen) at the present febrile episode }\end{array}$ \\
$\begin{array}{l}\text { Recurrent } \\
\text { cholecystitis- } \\
\text { cholangitis }\end{array}$ & 1 & $\begin{array}{c}\text { The diagnosis was confirmed on magnetic resonance cholangio-pancreaticography (MRCP) and required ERCP } \\
\text { (Endoscopic retrograde cholangio-pancreaticography) and stenting to decompress the bile duct; the present } \\
\text { febrile episode had the same etiology with blockage of the previous stent and required PTBD }\end{array}$ \\
\hline
\end{tabular}

$P T B D$ percutaneous trans-hepatic biliary drainage, URTI upper respiratory tract infection, UTI urinary tract infection 
Table 5 Demographic features, clinical profile and maternal outcomes of pregnant women with fever by three most common aetiologies

\begin{tabular}{|c|c|c|c|c|}
\hline & Total $(n=181) n(\%)$ & Dengue $(n=44) n(\%)$ & Hepatitis $E(n=26) n(\%)$ & $\mathrm{UTI}(n=22) n(\%)$ \\
\hline Primigravida \# & $80(44.2)$ & $17(38.6)$ & $11(42.3)$ & $13(59)$ \\
\hline Gestational age (weeks)* & $30(6-40)$ & $31(10-40)$ & $31(12-39)$ & $29(6-39)$ \\
\hline Duration of fever (days)* & $6(2-60)$ & $4(2-10)$ & $7(3-14)$ & $6(2-30)$ \\
\hline Temperature at admission $\left({ }^{\circ} \mathrm{F}\right)^{*}$ & $101.4(99-104)$ & $100.6(99-102)$ & $100.3(99-104)$ & $100.8(99.6-103)$ \\
\hline Haemoglobin $(\mathrm{g} / \mathrm{dL})^{* *}$ & $10(5-16)$ & $11(7.3-14.2)$ & $11(7.6-13.6)$ & $10.3(6.8-13.3)$ \\
\hline Total leucocyte count (per $\mu \mathrm{L})^{* *}$ & $11,900(2400-41,300)$ & $8350(3200-24,000)$ & $14,650(3200-34,400)$ & $18,900(4400-29,200)$ \\
\hline Platelet count $(\text { lacs } / \mu \mathrm{L})^{* *}$ & $1.7(0.1-8.3)$ & $0.97(0.05-3.8)$ & $1.85(0.49-3.2)$ & $2.1(0.6-8.3)$ \\
\hline Creatinine $(\mathrm{mg} / \mathrm{dL}) * *$ & $0.6(0.2-28)$ & $0.6(0.2-28)$ & $0.7(0.4-20)$ & $0.65(0.3-6.8)$ \\
\hline AST (IU/L)** & $79(15-10,547)$ & $78(26-10,547)$ & $537(51-7775)$ & $48(15-224)$ \\
\hline $\operatorname{ALT}(\mathrm{IU} / \mathrm{L})^{* *}$ & $54(5-5083)$ & $54(15-3521)$ & $568(100-5083)$ & $48(5-278)$ \\
\hline PTI $(\%)^{* *}$ & $100(10-100)$ & $100(33-100)$ & $65(19-86)$ & $100(56-100)$ \\
\hline ARDS \# & $28(15.5)$ & $8(18.2)$ & $2(7.6)$ & 0 \\
\hline AKI \# & $41(22.6)$ & $8(18.2)$ & $6(23.1)$ & $5(22.8)$ \\
\hline ALF \# & $40(22.1)$ & $4(9.1)$ & $2180.7)$ & $1(4.5)$ \\
\hline Encephalopathy\# & $34(18.8)$ & $5(11.4)$ & $8(30.7)$ & 0 \\
\hline WHO maternal near miss \# & $33(18.2)$ & $7(16)$ & $9(34.6)$ & $4(18.2)$ \\
\hline Duration of hospital stay (days)* & $7(1-52)$ & $9(1-52)$ & $7(1-12)$ & $8(1-27)$ \\
\hline Maternal death\# & $29(16)$ & $7(16)$ & $6(23.1)$ & 0 \\
\hline
\end{tabular}

$A K I$ Acute kidney injury, $A L F$ acute liver failure, $A L T$ alanine transaminase, $A R D S$ acute respiratory distress syndrome, $A S T$ aspartate transaminase, $P T I$ prothrombin index, LSCS lower segment caesarean section, UTI urinary tract infection

\#Percentage; denominator $=n($ Dengue $=44$, Hepatitis $E=26, \mathrm{UTI}=22)$

*Average (minimum value-maximum value)

**Median (minimum value-maximum value)

9 of $26(34.6 \%)$ cases, dengue in 7 of $44(15.9 \%)$ cases and tuberculosis in 5 of $11(45.5 \%)$ cases. Other causes of death were gastroenteritis, H1N1 infection and pneumonia in 2 patients each and hepatitis A and scrub typhus in 1 patient each. Pregnancy and feto-neonatal outcomes were assessed for 167 cases. Of the remaining 14 patients, 3 were lost to follow-up, 4 did not go into labour till the end of study period and 7 maternal deaths were recorded with undelivered foetus (Table 6). Maternal complications and predictors of maternal mortality are listed in Tables 7 and 8 , respectively.

\section{Discussion}

This study spanned a full year and thus covered all seasons. Since many febrile illnesses are seasonal, coverage of a full year removes this bias and reflects the true incidence of various causes of fever in our population. Diseases with strong seasonal variations were the most common causes of fever in pregnant women. As a group, mosquito-borne diseases and those transmitted by the feco-oral route were the most common. Thus, most cases of fever in pregnancy are preventable. This suggests that strengthening of the public health
Table 6 Pregnancy outcomes of women with fever

\begin{tabular}{lc}
\hline Outcomes & Frequency $n(\%)^{*}$ \\
\hline Miscarriage $(n=167)$ & $7(4.1)$ \\
Pre-term births $(n=167)$ & $72(43.1)$ \\
Oligohydramnios (on ultrasonography) $(n=150$, cases in late 2nd and 3rd trimester & $43(28.7)$ \\
$\quad$ only, where ultrasonography was possible $)$ & \\
Still births ( $n=167)$ & $20(11.9)$ \\
Low birth weight babies ( $n=160,167$ minus 7 abortions excluded) & $75(46.9)$ \\
Requirement of Neonatal ICU (NICU) care $(n=160,167$ minus 7 abortions excluded) & $31(22.1)$ \\
Neonatal death $(n=160,167$ minus 7 abortions excluded) & $9(6.4)$ \\
\hline
\end{tabular}

*overlapping incidences 
Table 7 Complications developing in the mother

\begin{tabular}{|c|c|c|c|c|}
\hline Complication & Number & $\%$ & Common etiology & Significant association \\
\hline $\begin{array}{l}\text { Acute respiratory } \\
\text { distress syndrome }\end{array}$ & 28 & 15.5 & $\begin{array}{l}\text { Dengue ( } 8 \text { patients), pneumonia and tubercu- } \\
\text { losis ( } 5 \text { patients each) }\end{array}$ & $\begin{array}{l}83.3 \% \text { of total pneumonia cases }(5 / 6), 66.7 \% \text { of total } \\
\text { H1N1 cases }(2 / 3)\end{array}$ \\
\hline Acute kidney injury & 41 & 22.7 & Dengue ( 8 patients), Hepatitis E (6 patients) & $66.7 \%$ of total $\mathrm{H} 1 \mathrm{~N} 1$ cases $(2 / 3)$ \\
\hline Liver failure & 40 & 22.1 & Hepatitis E (21 patients) & $\begin{array}{l}80.8 \% \text { of total hepatitis E cases }(21 / 26), 66.7 \% \text { of total } \\
\text { hepatitis A cases }(4 / 6), 66.7 \% \text { of total H1N1 cases }(2 / 3)\end{array}$ \\
\hline Encephalitis & 34 & 18.8 & Hepatitis E (8 patients) & $\begin{array}{l}50 \% \text { of total hepatitis A cases }(3 / 6), 30.8 \% \text { of total hepati- } \\
\text { tis E cases }(8 / 26)\end{array}$ \\
\hline Severe sepsis & 75 & 41.4 & Dengue (18 patients), hepatitis E (15 patients) & $\begin{array}{l}83.3 \% \text { of total pneumonia cases }(5 / 6), 54.5 \% \text { of total } \\
\text { tuberculosis cases }(6 / 11), 66.7 \% \text { of total H1N1cases } \\
(2 / 3)\end{array}$ \\
\hline
\end{tabular}

Table 8 Predictors of maternal mortality

\begin{tabular}{lc}
\hline & $p$ value \\
\hline Findings at admission & \\
Duration of fever $>7$ days & 0.002 \\
Dyspnoea & 0.031 \\
Seizures & 0.000 \\
Altered sensorium & 0.000 \\
Mean arterial pressure $\leq 65 \mathrm{mmHg}$ & 0.000 \\
Respiratory rate $>24 / \mathrm{min}$ & 0.000 \\
$\mathrm{O}_{2}$ saturation $<90 \%$ & 0.000 \\
Glasgow coma scale $(\mathrm{GCS})<15$ & 0.000 \\
Laboratory investigations & \\
Total leucocyte count $<4000 / \mu \mathrm{L}$ & 0.048 \\
Platelet count $<1$ lac/ $/ \mu \mathrm{L}$ & 0.020 \\
Serum creatinine $\geq 1.5 \mathrm{mg} / \mathrm{dL}$ & 0.018 \\
AST $>3$ times upper limit of normal & 0.024 \\
ALT $>3$ times upper limit of normal & 0.024 \\
INR $>1.2$ & 0.000 \\
Final diagnosis & \\
H1N1 influenza & 0.016 \\
Tuberculosis & 0.006 \\
\hline
\end{tabular}

infrastructure can effectively reduce the incidence of fever and improve maternal and foetal outcomes. Use of mosquito nets and supply of potable water are likely to prevent febrile illness in a majority of cases. The overall maternal mortality was $16 \%$. Our institute being a referral centre gets sicker patients which is likely the cause for a high maternal mortality.

Dengue was overall the most common cause of fever among pregnant women being responsible for almost a quarter of patients. Other common aetiologies were hepatitis E infection and UTI. Previous studies from tropics have found malaria to be the commonest cause of fever in pregnancy [7-9]. In our study, dengue was by far the commonest vector-borne disease with malaria forming only $6.1 \%$ cases. Dengue was associated with significant morbidity and mortality. $15.9 \%$ patients died, and another
$15.9 \%$ were classified as maternal near-miss cases. This suggests that dengue is more severe in pregnant patients [10-12]. Potential referral of sicker patients to a tertiary care centre could confound the results. With an increasing annual incidence of dengue nation-wide, and observations of adverse maternal and foetal outcomes of pregnancy, seasonal preventive measures should be instituted and referral and management protocols standardized for optimal and timely management of pregnant women with dengue.

Hepatitis E was the second most frequent cause of fever during pregnancy, which is understandable as India is hyperendemic to hepatitis E virus [13]. This is again a preventable condition. In our study, a high rate of maternal and foetal complications was recorded with a maternal mortality of $23.1 \%$. Poor maternal-foetal outcomes with hepatitis E infection in pregnant women have been well reported with high case fatality rates, and foetal complications include still births, miscarriages and risks of vertical transmission $[14,15]$. Hepatitis A and hepatitis B were less common and encountered in $3.3 \%$ and $0.6 \%$ patients, respectively. No patient with hepatitis $\mathrm{C}$ was seen.

UTI was found to be the third most frequent cause. There were no maternal deaths, but adverse foetal outcomes including pre-term births and low birth weight babies were seen. Adverse pregnancy outcomes in pregnant women with UTI have similarly been previously reported [16]. This suggests the need for promotion of screening urine cultures during pregnancy to detect asymptomatic bacteriuria and use of bacterial sensitivity guided antibiotic use in pregnant women with UTI.

Both pulmonary tuberculosis and extra-pulmonary tuberculosis were encountered, and all patients were treated with modified DOTS regimen anti-tubercular therapy. Studies have found that with early initiation of therapy, pregnancy does not adversely affect tuberculosis [17]. However, our patients commonly had adverse outcomes, likely because they were referred at a late stage. There is resurgence in the cases of scrub typhus in the country, and we encountered 6 patients with scrub typhus during pregnancy. 
The strengths of our study include its large sample size and the thorough investigative process that was carried out with only 3 cases remained undiagnosed. Important limitations of this study include the hospital-based nature of this study, and hence, this study does not evaluate the profile of pregnant women with fever in the community. Also, ours is a regional referral and training centre; therefore, it is likely that a large number of complicated patients are referred to our institute and may not be representative of true complication rates in the community.

To conclude, dengue, hepatitis E and UTI were the most common causes of fever during pregnancy. Most cases were caused by vector- and water-borne diseases and are potentially preventable. The maternal mortality rate was high at $16 \%$. Common causes of death were hepatitis $\mathrm{E}$ infection, dengue and tuberculosis.

\section{Acknowledgements None}

Funding None.

\section{Declarations}

Conflict of interest The authors declare that they have no conflict of interest.

Ethical Approval The study was approved by the Institutional Ethics Committee, PGIMER, Chandigarh Vide Numbers INT/IEC/2017/1116 dated 21.10. 2017. The study has been performed in accordance with the ethical standards laid down in the 1964 Declaration of Helsinki and its later amendments.

Informed Consent Written informed consent was obtained from all subjects.

\section{References}

1. Sappenfield E, Jamieson DJ, Kourtis AP. Pregnancy and susceptibility to infectious diseases. Infect Dis Obstet Gynecol. 2013;2013:752852. https://doi.org/10.1155/2013/752852.

2. Kourtis AP, Read JS, Jamieson DJ. Pregnancy and infection. N Engl J Med. 2014;370:2211-8. https://doi.org/10.1056/NEJMr a1213566.

3. Biswas J, Banerjee K, Sanyal P, et al. Fetomaternal outcome of pyrexia in pregnancy: a prospective study. Int $\mathrm{J}$ Womens Health Reprod Sci. 2015;3:132-5. https://doi.org/10.15296/ijwhr.2015. 28.

4. Kansal A, Garg S, Sharma M. Moving from maternal death review to surveillance and response: a paradigm shift. Indian J Public Health. 2018;62:299-301. https://doi.org/10.4103/ijph.IJPH_37_ 18.

5. Hartgill TW, Bergersen TK, Pirhonen J. Core body temperature and the thermoneutral zone: a longitudinal study of normal human pregnancy. Acta Physiol. 2011;201:467-74. https://doi.org/10. 1111/j.1748-1716.2010.02228.x.

6. Sund-Levander M, Forsberg C, Wahren LK. Normal oral, rectal, tympanic and axillary body temperature in adult men and women: a systematic literature review. Scand J Caring Sci. 2002;16:122-8. https://doi.org/10.1046/j.1471-6712.2002.00069.x.
7. Takem EN, D’Alessandro U. Malaria in pregnancy. Mediterr J Hematol Infect Dis. 2013;5:e2013010. https://doi.org/10.4084/ MJHID.2013.010.

8. McGready R, Nosten F, Barnes KI, et al. Why is WHO failing women with falciparum malaria in the first trimester of pregnancy? Lancet. 2020;395(10226):779. https://doi.org/10.1016/ S0140-6736(20)30161-6.

9. Fowkes FJI, Davidson E, Moore KA, et al. The invisible burden of malaria-attributable stillbirths. Lancet. 2020;395(10220):268 https://doi.org/10.1016/S0140-6736(19)33011-9.

10. Paixão ES, Teixeira MG, Costa MDCN, et al. Dengue during pregnancy and adverse fetal outcomes: a systematic review and meta-analysis. Lancet Infect Dis. 2016;16:857-65. https://doi.org/ 10.1016/S1473-3099(16)00088-8.

11. Paixão ES, Costa MDCN, Harron TMG, et al. Symptomatic dengue infection during pregnancy and the risk of stillbirth in Brazial, 2006-12: matched case-control study. Lancet Infect Dis. 2017;17:957-64. https://doi.org/10.1016/S1473-3099(17)30366-3.

12. Paixão ES, Campbell OM, Teixeira MG, et al. Dengue during pregnancy and live birth outcomes: a cohort of linked data from Brazil. BMJ Open. 2019;9:e023529. https://doi.org/10.1136/ bmjopen-2018-023529.

13. Jain P, Prakash S, Gupta S, et al. Prevalence of hepatitis A virus, hepatitis $B$ virus, hepatitis $C$ virus, hepatitis $D$ virus and hepatitis $E$ virus as causes of acute viral hepatitis in North India: a hospital based study. Indian J Med Microbiol. 2013;31:261-5. https://doi. org/10.4103/0255-0857.115631.

14. Kashyap R, Joshi I, Gupta D, et al. Characteristics and obstetric outcomes in pregnant women with acute hepatitis $\mathrm{E}$ virus infection in tertiary care hospital of himachal Pradesh. J Assoc Phys India. 2019;67(4):20-2.

15. Bergløv A, Hallager S, Weis N. Hepatitis E during pregnancy: Maternal and foetal case-fatality rates and adverse outcomes: a systematic review. J Viral Hepat. 2019;26:1240-8. https://doi.org/ 10.1111/jvh.13129.

16. Szweda H, Jóźwik M. Urinary tract infections during pregnancy: an updated overview. Dev Period Med. 2016;20(4):263-72.

17. Chopra S, Siwatch S, Aggarwal N, et al. Pregnancy outcomes in women with tuberculosis: a 10-year experience from an Indian tertiary care hospital. Trop Doct. 2017;47:104-9. https://doi.org/ $10.1177 / 0049475516665765$.

Publisher's Note Springer Nature remains neutral with regard to jurisdictional claims in published maps and institutional affiliations.

\section{About the Author}

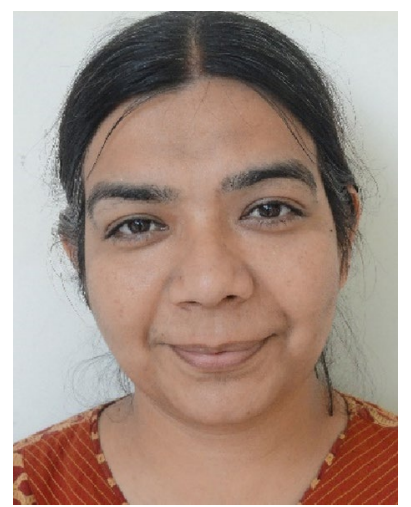

Dr. Pooja Sikka is additional professor in the department of obstetrics and gynaecology, Postgraduate Institute of Medical Education and Research, Chandigarh. Her area of interest is medical disorders in pregnancy. 